\title{
Antagonism in the carbon footprint between beef and dairy production systems
}

\author{
M.M. Scholtz ${ }^{1,2 \#}$, J. du Toit ${ }^{1}$ \& F.W.C.Neser ${ }^{2}$ \\ ${ }^{1}$ ARC-Animal Production Institute, Private Bag X2, Irene 0062, South Africa \\ ${ }^{2}$ University of the Free State, P.O. Box 339, Bloemfontein 9300, South Africa
}

(Received 4 January 2014; Accepted 5 June 2014; First published online 22 August 2014)

\begin{abstract}
Copyright resides with the authors in terms of the Creative Commons Attribution 2.5 South African Licence.
See: http://creativecommons.org/licenses/by/2.5/za

Condition of use: The user may copy, distribute, transmit and adapt the work, but must recognise the authors and the South African Journal of Animal Science.
\end{abstract}

\begin{abstract}
Primary beef cattle farming in South Africa is largely extensive, whereas dairy farming is based on both total mixed ration and pasture production systems. Under natural rangeland conditions, decomposition of manure is aerobic, which produces carbon dioxide $\left(\mathrm{CO}_{2}\right)$, part of which is absorbed by the regrowth of vegetation rather than released into the atmosphere, and water $\left(\mathrm{H}_{2} \mathrm{O}\right)$ as end products. Thus the cow releases methane $\left(\mathrm{CH}_{4}\right)$ and the manure $\mathrm{CO}_{2}$. This is in contrast to intensive cow-calf systems in large parts of Europe and North America, where large quantities of manure are stockpiled and undergo anaerobic decomposition and produce $\mathrm{CH}_{4}$. Thus both the cow and the manure release $\mathrm{CH}_{4}$, which result in a higher carbon footprint than the extensive cow-calf systems. In dairy farming, increasing cow efficiency through intensive feeding (same $\mathrm{kg}$ milk output by fewer animals) can reduce farm $\mathrm{CH}_{4}$ production by up to $15 \%$. In addition, when differences in productivity are accounted for, pasture systems require more resources (land, feed, water, etc.) per unit of milk produced and the carbon footprint is greater than that of intensive systems. This raises the question as to why the carbon footprint of intensive dairy cow production systems is less, but the carbon footprint of intensive beef cow-calf production systems is higher. The explanation lies in the differences in production levels. In the case of beef cows the weight of the intensive cows will be $\pm 30 \%$ higher than that of the extensive cows, and the weaning weight of their calves will also differ by $\pm 30 \%$. In the case of dairy cows the weight of the intensive cows will be $\pm 20 \%$ higher, but their milk production will be \pm $60 \%$ higher. The higher increase in production (milk) of intensive dairy cows, compared to the increase in production (calf weight) of intensive beef cows, explains the antagonism in the carbon footprint between different beef and dairy production systems. Unfortunately, carbon sequestration estimates have been neglected and thus the quantitative effects of these differences are not known.
\end{abstract}

Keywords: Cow-calf production, methane, pasture production, production levels, total mixed ration

\# Corresponding author: GScholtz@arc.agric.za

\section{Introduction}

In South Africa, the cow-calf production cycle is mostly extensive, since large parts of the country are not suitable for crop cultivation, with approximately only $13 \%$ that can be cultivated. The greater part of South Africa (71\%) is thus only suitable for extensive livestock farming (RMRD SA, 2013). Under these natural rangeland conditions, decomposition of manure is aerobic, leading to the production of carbon dioxide $\left(\mathrm{CO}_{2}\right)$ and water $\left(\mathrm{H}_{2} \mathrm{O}\right)$ as end products. Thus where the cow emits methane $\left(\mathrm{CH}_{4}\right)$, the manure releases $\mathrm{CO}_{2}$. It is important to note that part of the $\mathrm{CO}_{2}$ from the manure is most likely absorbed by the regrowth of the surrounding vegetation rather than released into the atmosphere. This is in sharp contrast to the intensive systems in large parts of Europe and North America, where large quantities of manure are stockpiled and undergo anaerobic decomposition. The anaerobic decomposition of manure in these intensive cow-calf systems, feedlots and intensive dairy systems then produce $\mathrm{CH}_{4}$ as one of the major end products (Scholtz et al., 2013).

Although the primary beef cattle cow-calf production cycle is largely extensive in South Africa, more than $75 \%$ of the cattle slaughtered in the formal sector are finished in feedlots (RMRD SA, 2013), over a fattening period of approximately 110 days, which means that they produce greenhouse gases (GHG) for only 110 days before being slaughtered. Cattle on rangeland/pastures in South Africa require more than 200 days of finishing before reaching the same carcass classification, because of the lower quality feed, than in a feedlot diet. The lower quality feed (mainly natural pastures consumed) also produce more GHG per 
kilogram feed intake than the concentrates used in the feedlots (Capper, 2011; Meissner et al., 2012). The bottom line is that feedlots maximize the efficiency of meat production, resulting in a lower carbon footprint.

With respect to dairy cows, both total mixed ration (TMR) and pasture production systems, or a combination thereof, are followed in South Africa, depending on the region. There is substantial evidence that cows on pastures produce more $\mathrm{CH}_{4}$ than cows on high concentrate diets (Gibson, 2010). For example, Capper et al. (2009) indicated that in the USA the carbon footprint per kilogram milk produced in 2007 was only $37 \%$ of that produced in 1944 . The carbon footprint of milk that is currently produced is $63 \%$ smaller than the mostly natural production systems of 1944. Other studies in the USA confirmed that milk production is $15 \%-27 \%$ lower in organic than in conventional systems (Meissner et al., 2012) and when differences in productivity were accounted for, the organic systems required more resources (land, feed, water, etc.) per unit of milk produced and the environmental impact was greater. This implies that milk from TMR systems has a lower carbon footprint than pasture based systems.

This raises the question as to why the carbon footprint of milk from intensive dairy cows is less than that of pasture dairy cows, but in the case of beef cows the carbon footprint of beef from extensive cow-calf production systems is lower than that of intensive cow-calf production systems. Due to this potential confusion, this paper attempts to explain this antagonism between beef and dairy production systems.

\section{Materials and Methods}

Information was collected to compare animal weights and production levels between intensive and extensive production systems of beef and dairy cows.

Cow and calf weights for extensive and intensive cow-calf beef production systems were taken from Scholtz (2010), where the information of commercial cows participating in performance recording was used; and from (www.angus.org) where the information of Angus cows in the USA were used. This information is summarized in Table 1.

Table 1 Summary of cow and calf weights of extensive and intensive cow-calf beef production systems

\begin{tabular}{lccc}
\hline & \multicolumn{2}{c}{ Cow-calf production system } & \% \\
& Intensive & Extensive & Difference \\
\hline Cow weight $(\mathrm{kg})$ & 650 & 520 & $31 \%$ \\
Calf weaning weight $(\mathrm{kg})$ & 295 & 220 & $33 \%$ \\
\hline
\end{tabular}

Cow weights and production levels were collected from 3625 Holstein cows on TMR and 863 Holstein cows on pastures from farms in the southern and western Cape of South Africa that use the Afikim milking system. This information is summarized in Table 2.

Table 2 Summary of cow weights and milk production of TMR and pasture based milk production systems

\begin{tabular}{|c|c|c|c|}
\hline & \multicolumn{2}{|c|}{ Dairy production system } & \multirow{2}{*}{$\begin{array}{c}\% \\
\text { Difference }\end{array}$} \\
\hline & TMR & Pasture based & \\
\hline Cow weight (kg) & 665 & 560 & $19 \%$ \\
\hline Milk production $(\mathrm{kg})$ & 11600 & 7200 & $62 \%$ \\
\hline
\end{tabular}

\section{Results and Discussion}

From Table 1 it is clear that the cow and calf weights increase with almost the same percentage from the extensive to the intensive cow-calf production system. From Table 2 it is clear that although cow weight between the two production systems differs with only $19 \%$, the difference in milk production was a very high $62 \%$. The information from Tables 1 and 2 were then used to simulate the number of cows needed to produce (1) $30000 \mathrm{~kg}$ of weaner calf and (2) $1000000 \mathrm{~kg}$ of milk and the results are presented in Table 3. 
The conclusion from these results is that intensive cattle production systems will have a lower carbon footprint than extensive production systems, if the production period can be shortened (as is the case with feedlots) or the production per unit (as is the case with the TMR systems) can be significantly increased. Du Toit et al. (2013) estimated the methane emission factor for dairy cattle on a TMR to be $76.4 \mathrm{~kg}$ $\mathrm{CH}_{4} /$ head/year and for those on pasture based systems, as $71.84 \mathrm{~kg} \mathrm{CH} / \mathrm{head} /$ year. Although the methane emission factor for dairy cattle on pasture based systems is slightly lower, the production levels are much lower, resulting in a higher carbon footprint for milk produced from pastures.

Table 3 The number of cows needed for specific production targets from intensive and extensive production systems

(1) Number of cows needed to produce $30000 \mathrm{~kg}$ of weaner calf

\begin{tabular}{lcc}
\hline Intensive & 102 & $\begin{array}{c}\text { A difference of } 34 \text { cows } \\
\text { or } 33 \%\end{array}$ \\
Extensive & 136 & A difference of 53 cows \\
& $(2)$ & Number of cows needed to produce $\mathbf{1 0 0 0 0 0 0 ~ k g ~ o f ~ m i l k ~ p e r ~ l a c t a t i o n ~}$ \\
\hline TMR & 86 & or \\
Pasture & 139 & \\
\hline
\end{tabular}

\section{Conclusion}

The bottom line is that if production levels are not significantly increased or the production period not decreased through intensive production systems, the extensive production systems e. g. the extensive beef cow-calf production cycle in South Africa, will not have a lower carbon footprint, since part of the $\mathrm{CO}_{2}$ from manure is absorbed by the regrowth of the surrounding vegetation rather than released into the atmosphere. Unfortunately, carbon sequestration estimates have been largely neglected and thus the quantitative effects of these differences are not known.

\section{Acknowledgement}

This work is based on research supported in part by Red Meat Research and Development South Africa and the National Research Foundation of South Africa (NRF), under grant UID 75123. The Grantholder acknowledges that opinions, findings and conclusions or recommendations expressed in any publication generated by the NRF supported research are that of the authors and that the NRF accepts no liability whatsoever in this regard.

\section{References}

Capper, J.L., 2011. Replacing rose-tinted spectacles with a high-powered microscope: The historical versus modern carbon footprint of animal agriculture. Anim. Front. 1, 26-32.

Capper, J.L., Cady, R.A. \& Bauman, D.E., 2009. The environmental impact of dairy production: 1944 compared with 2007. J. Anim. Sci. 87, 2160-2167.

Du Toit, C.J.L, Meissner, H.H. \& Van Niekerk, W.A., 2013. Direct methane and nitrous oxide emissions of South African dairy and beef cattle. S. Afr. J. Anim. Sci. 42, 320-339.

Gibson, J., 2010. Open Discussion: Will Genetic Improvement Make a Significant Contribution to Reduction in Greenhouse Gas Emissions in Livestock? $9^{\text {th }}$ Wrld Congr. Genet. Appl. Livest. Prod. Available at: www.wcgalp2010.org. Accessed: 25 May 2012.

Meissner, H.H., Scholtz, M.M. \& Schönfeldt, H.C., 2012. The status, socio-economic and environmental impact, and challenges of livestock agriculture in South Africa. Available at: www.rmrdsa.co.za Accessed: 25 April 2013.

RMRD SA, 2013. Research and Development Plan for the Large and Small Stock Meat Industries in South Africa, 2012-2013. Available at: www.rmrdsa.co.za Accessed: 25 April 2013. 
Scholtz, M.M., 2010. Beef Breeding in South Africa, 2010, 2nd Edition. Agricultural Research Council, Pretoria, South Africa.

Scholtz, M.M., Van Ryssen, J.B.J., Meissner, H.H. \& Laker, M.C., 2013. A South African perspective on livestock production in relation to greenhouse gases and water usage. S. Afr. J. Anim. Sci. 43, 247-254. 